\title{
Multinational Association of Supportive Care in Cancer (MASCC) 2020 clinical practice recommendations for the management of immune-related adverse events: pulmonary toxicity
}

\author{
Vickie R. Shannon ${ }^{1}$ - Ronald Anderson ${ }^{2} \cdot$ Ada Blidner $^{3}$ • Jennifer Choi ${ }^{4} \cdot$ Tim Cooksley $^{5,6} \cdot$ Michael Dougan $^{7,8}$. \\ Ilya Glezerman ${ }^{9}$. Pamela Ginex ${ }^{10}$. Monica Girotra ${ }^{11,12}$ - Dipti Gupta ${ }^{12}$. Douglas B. Johnson ${ }^{13}$. \\ Maria E. Suarez-Almazor ${ }^{14}$. Bernardo L. Rapoport ${ }^{2,15}$ (DD
}

Received: 24 April 2020 / Accepted: 20 August 2020 / Published online: 3 September 2020

(C) Springer-Verlag GmbH Germany, part of Springer Nature 2020

\begin{abstract}
The immune checkpoints associated with the CTLA- 4 and PD-1 pathways are critical modulators of immune activation. These pathways dampen the immune response by providing brakes on activated $\mathrm{T}$ cells, thereby ensuring more uniform and controlled immune reactions and avoiding immune hyper-responsiveness and autoimmunity. Cancer cells often exploit these regulatory controls through a variety of immune subversion mechanisms, which facilitate immune escape and tumor survival. Immune checkpoint inhibitors (ICI) effectively block negative regulatory signals, thereby augmenting immune attack and tumor killing. This process is a double-edged sword in which release of regulatory controls is felt to be responsible for both the therapeutic efficacy of ICI therapy and the driver of immune-related adverse events (IrAEs). These adverse immune reactions are common, typically low-grade and may affect virtually every organ system. In the early clinical trials, lung IrAEs were rarely described. However, with ever-expanding clinical applications and more complex ICI-containing regimens, lung events, in particular, pneumonitis, have become increasingly recognized. ICI-related lung injury is clinically distinct from other types of lung toxicity and may lead to death in advanced stage disease. Thus, knowledge regarding the key characteristics and optimal treatment of lung-IrAEs is critical to good outcomes. This review provides an overview of lung-IrAEs, including risk factors and epidemiology, as well as clinical, radiologic, and histopathologic features of ICI-related lung injury. Management principles for ICIrelated lung injury, including current consensus on steroid refractory pneumonitis and the use of other immune modulating agents in this setting are also highlighted.
\end{abstract}

Keywords Cancer · Drug-induced pneumonitis · Drug toxicity $\cdot$ Immune-related adverse events (IrAEs) $\cdot$ Immune checkpoint inhibitors $\cdot$ Immunotherapy

\author{
Bernardo L. Rapoport \\ bernardo.rapoport@up.ac.za \\ Vickie R. Shannon \\ vshannon@mdanderson.org \\ Ronald Anderson \\ ronald.anderson@up.ac.za \\ Ada Blidner \\ adablidner@gmail.com \\ Jennifer Choi \\ jennifer.choi@northwestern.edu \\ Tim Cooksley \\ cooks199@hotmail.com \\ Michael Dougan \\ mldougan@partners.org
}

\author{
Ilya Glezerman \\ Glezermi@mskcc.org \\ Pamela Ginex \\ pginex@ons.org \\ Monica Girotra \\ girotram@mskcc.org \\ Dipti Gupta \\ guptad@mskcc.org \\ Douglas B. Johnson \\ douglas.b.johnson@vumc.org \\ Maria E. Suarez-Almazor \\ msalmazor@mdanderson.org
}

Extended author information available on the last page of the article 


\section{Introduction}

A growing wealth of evidence supports immune surveillance and immune tolerance as key players in cancer development and progression. These observations have led to renewed interest in developing strategies that harness endogenous immunity and tilt immune equilibrium in favor of enhanced tumor killing. One such strategy has been the exploitation of tumorassociated ligands and their corresponding inhibitory receptors on $\mathrm{T}$ cells, collectively known as immune checkpoints. Immune checkpoints associated with the CTLA-4 and PD-1 pathways are critical modulators of immune activation, both acting to dampen the immune response. Mutant cancer cells may effectively "hijack" immune checkpoint activation through PD-1 and CTLA-4 pathways, allowing tumor cells to evade normal immune surveillance and escape immune destruction by anti-tumor $\mathrm{T}$ lymphocytes. Recognition of PD-1 and CTLA-4 pathways as druggable targets in anticancer therapy has led to the successful launching of a new class of drugs, referred to as immune checkpoint inhibitors (ICIs). Over the past decade, a rapidly evolving list of ICIs, including the CTLA-4 inhibitor, ipilimumab; the PD-1 inhibitors, nivolumab and pembrolizumab; and the PD-L1 inhibitors, atezolizumab, avelumab, and durvalumab have been FDA-approved in the management of a variety of solid and hematologic malignancies. These agents represent a paradigm shift in which the T cell, rather than the cancer cell, represents the therapeutic target.

The use of the body's own immune defense system to fight cancer has ushered in a unique spectrum of immune-related adverse reactions (IrAEs), which can affect virtually every organ system. Lung-related IrAEs are, fortunately, less common than toxicities to other organ systems; however, toxicity to the lung represents a potentially lethal form of IrAEs and one of the most frequent causes of drug discontinuation. Pneumonitis is often reported [1-9], although pleural [10], vascular [11,12], airway, and sarcoid-like reactions associated with mediastinal lymphadenopathy have also been described [13-16].

\section{IrAEs: pneumonitis}

Stratification schemes that characterize pneumonitis severity are based on clinical symptoms in accordance with the common terminology criteria for adverse events (CTCAE). Hence, grade 1 pneumonitis represents radiographic changes without associated symptoms. Patients with grade 2 pneumonitis have mild dyspnea and/or cough. High-grade pneumonitis is indicated by severe or medically significant symptoms that are not immediately life threatening (grade 3) and life-threatening symptoms that require urgent medical attention (grade 4).
Rates of pneumonitis appear to be conditioned by the ICI drug class, as well as the histologic type of tumor being treated. PD-1 and PD-L1 inhibitor therapies confer a higher incidence of any grade pneumonitis (2.7-5\%), as well as highgrade pneumonitis $(0.8-2.0 \%)$, compared to CTLA-4 blocking agents ( $1.3 \%$ all grade, $0.3 \%$ high grade) when either approach is given as monotherapy [6,17-21]. Rates of pneumonitis are significantly increased with PD-1 or PD-L1 plus CTLA-4 inhibitor combinations, approaching $10 \%$ in some studies $[6,17,22-26]$ and Fig. 1. Pneumonitis following combination therapy is often more severe, with slower recovery periods than with monotherapy $[6,23]$. Details regarding the role of CTLA-4 inhibitors in augmenting the rate and severity of pneumonitis when given in combination with PD-1/PD-L1 blocking agents have not been fully elucidated; however, clinicians should be aware of the significantly higher incidence of pneumonitis during combination therapy and patients should be closely monitored for associated signs and symptoms. In contrast to conventional chemotherapies and target therapies, ICI therapy may elicit durable effects and toxicities well beyond discontinuation of the drug, due to the induction of immunologic memory [27]. As a result, increased rates of pneumonitis following sequential PD-1/PD-L1 or CTLA-4 monotherapies appear similar to pneumonitis rates when ICI combinations are given concomitantly (Fig. 1).

IrAE profiles across different ICI classes appear to be driven by variations in ICI class-specific immune cell activation. For example, the greater risk of pneumonitis with agents targeting the PD-1/PD-L1 axis may be due to activation of lung macrophages $[28,29]$. Notable differences in the prevalence of pneumonitis have also been suggested within the PD1/PD-L1 agent class, with higher rates of all grade, as well as high grade, pneumonitis reported in association with drugs that block the PD-1 axis compared to PD-L1 antagonists $[22,30]$. However, other studies have not corroborated these observations [17]. Unlike CTLA-4-related pneumotoxicity, which appears to be dose-related, no associations between the appearance and severity of pneumonitis and the dose of PD-1/PD-L1 axis blocking agents have been reported [31, 32].

The influence of tumor histology in the development of ICI-related pneumonitis has been increasingly recognized, with the highest incidence among patients with lung and renal cell cancers compared to other tumor types, such as melanoma $[5,6,25]$. The driving forces for variations in the prevalence of pneumonitis among different tumor types are not fully understood. Existing tumor burden in the lung, prior lung irradiation, and co-morbidities, such as COPD among lung cancer patients, may limit the lung's tolerance to additional injury and explain the higher rates of pneumonitis in this group of patients $[33,34]$. However, these co-morbid conditions may not be applicable for PD-1-treated patients with renal cancer, where the rates of pneumonitis are also high. Neo-antigen 

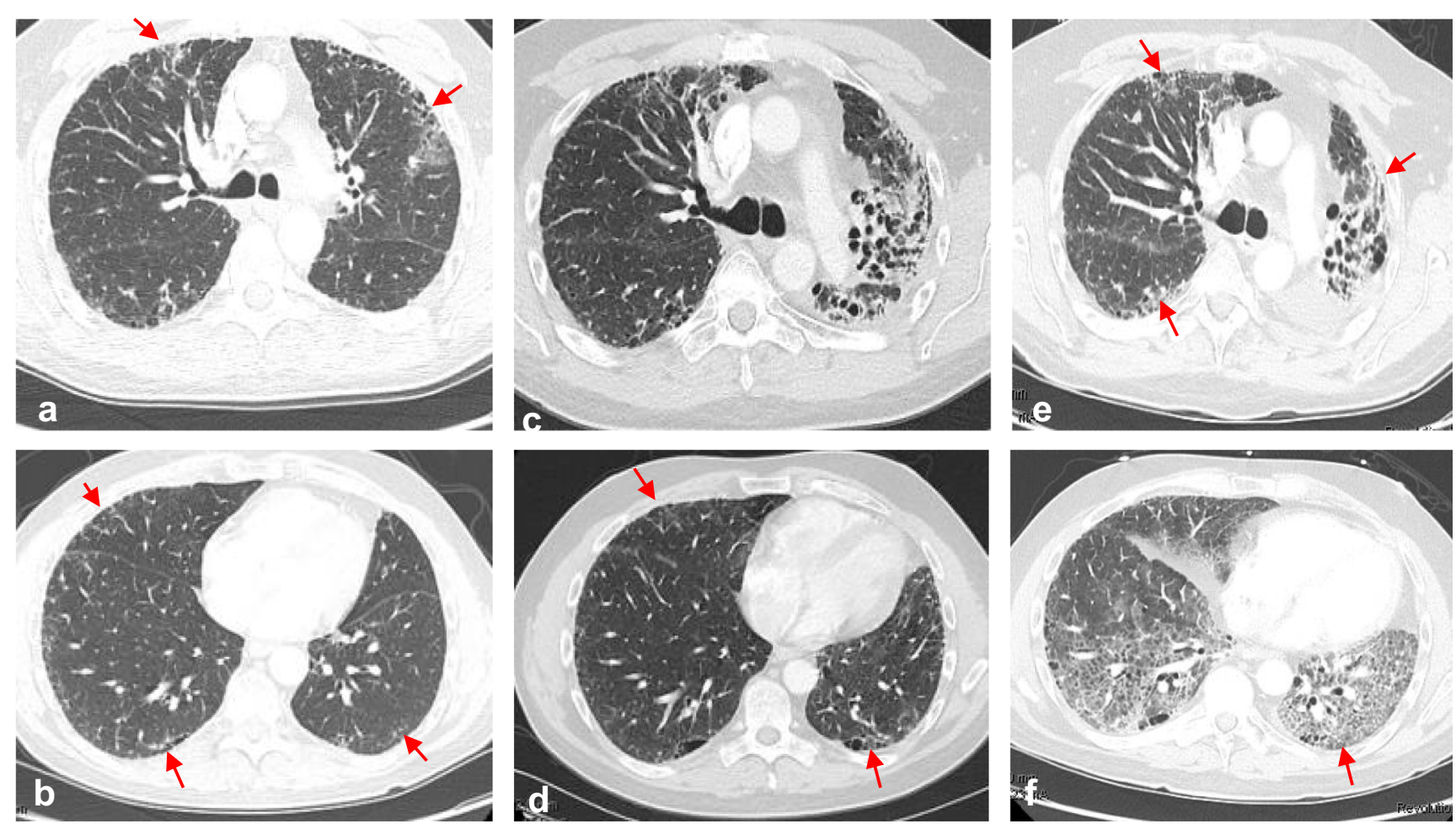

Fig. 1 Accelerated lung injury following sequential ICI therapy. A 60year-old man with metastatic urothelial carcinoma was treated with Pembrolizumab after failing standard chemotherapy. Pembrolizumab was interrupted after cycle 2 due to increased shortness of breath. Baseline CT imaging showed bilateral subpleural reticulations over the upper and lower lobes, consistent with his known history of idiopathic pulmonary fibrosis (a, b). Repeat CT imaging after cycle 2 of Pembrolizumab showed marked increase in diffuse upper and lower lobe and bilateral ground glass opacities $(\mathbf{c}, \mathbf{d})$. Symptoms and ground glass findings on CT nearly completely resolved with drug withdrawal

formation, the adaptive immune response, immune infiltrates, and the tumor microenvironment are all influenced by tumor histology and may offer additional explanations for the diversity of toxicity risk across different tumor types. Pre-existing fibrotic lung disease and a history of current or prior tobacco use have been implicated in the development of ICI-related pneumotoxicity, although details of these associations have yet to be defined clearly (Fig. 2) [17, 35].

Other risk factors of uncertain significance include preexisting autoimmune disorders, chronic viral syndromes, solid organ, or hematopoietic stem cell transplantation, as patients with these disorders were excluded from early clinical trials. Nonetheless, evidence from several small retrospective studies suggests that patients with pre-existing autoimmune disorders may be safely treated with ICI therapies. Severe and/or fatal pneumonitis in this setting has been reported rarely, thus underscoring the need for vigilance in carefully selecting and monitoring these patients [36-38]. Fatal IrAEs associated with severe graft versus host disease following hematopoietic stem cell transplantation in patients with hematologic malignancies who had been previously exposed to ICI therapies have raised and systemic corticosteroids. The PD-L1 inhibitor, durvalumab, given as monotherapy, was subsequently initiated. Three weeks after cycle 1 of durvalumab, severe and progressive symptoms of dyspnea, dry cough and hypoxia developed, resulting in admission and intubation for hypoxemic respiratory failure. All cultures were negative and no malignant cells were seen on BAL fluid. The patient continued to deteriorate despite high-dose steroids, antibiotics, and aggressive supportive care and later expired. An autopsy report confirmed diffuse alveolar damage with pulmonary fibrosis felt to be related to ICI therapy

concerns regarding the use of ICIs in this setting [39, 40]. These observations are concerning, particularly in the light of emerging evidence that supports the use of PD-1 inhibitors in the treatment of hematologic malignancies [41-43]. Several small case reports have also suggested that ICI therapy may be safe in selected patients with chronic viral illnesses, such as human immunodeficiency virus infection or hepatitis C [44, 45]. However, further prospective investigations are needed and the importance of multidisciplinary collaborations involving the oncologist, pulmonologist, liver, and infectious disease specialists cannot be over-emphasized. In several retrospective studies, ICI blockade in patients with pre-existing autoimmune disease elicited new IrAEs, transient flare-ups of preexisting autoimmune disease, or both. New IrAEs and disease exacerbations were mild in most cases, although rare cases of severe and fatal pneumonitis have been reported [36-38, 46].

Immune-related pneumonitis (Ir-pneumonitis) refers to a non-infective inflammatory response that localizes to the interstitium and alveoli and results in a diverse spectrum of CT findings and histopathologic patterns. These changes are collectively referred to as interstitial lung disease (ILD). Three 
Fig. 2 Ipilimumab-related accelerated lung injury in a patient with preexisting pulmonary fibrosis. Severe cough and dyspnea developed 3 weeks after initiation of ipilimumab monotherapy for metastatic prostate cancer. At baseline (a, b), CT imaging showed mild fibrotic changes, consistent with the patient's known history of idiopathic pulmonary fibrosis. The chest $\mathrm{CT}$ on admission showed significant progression of pulmonary fibrosis $(\mathbf{c}, \mathbf{d})$ in the upper and lower lobes, which progressed despite withdrawal of the agent and initiation of highdose steroids. BAL fluids were culture negative. Lung biopsies demonstrated interstitial inflammation and fibrosis, consistent with NSIP, which was thought to be due to Ipilimumab therapy
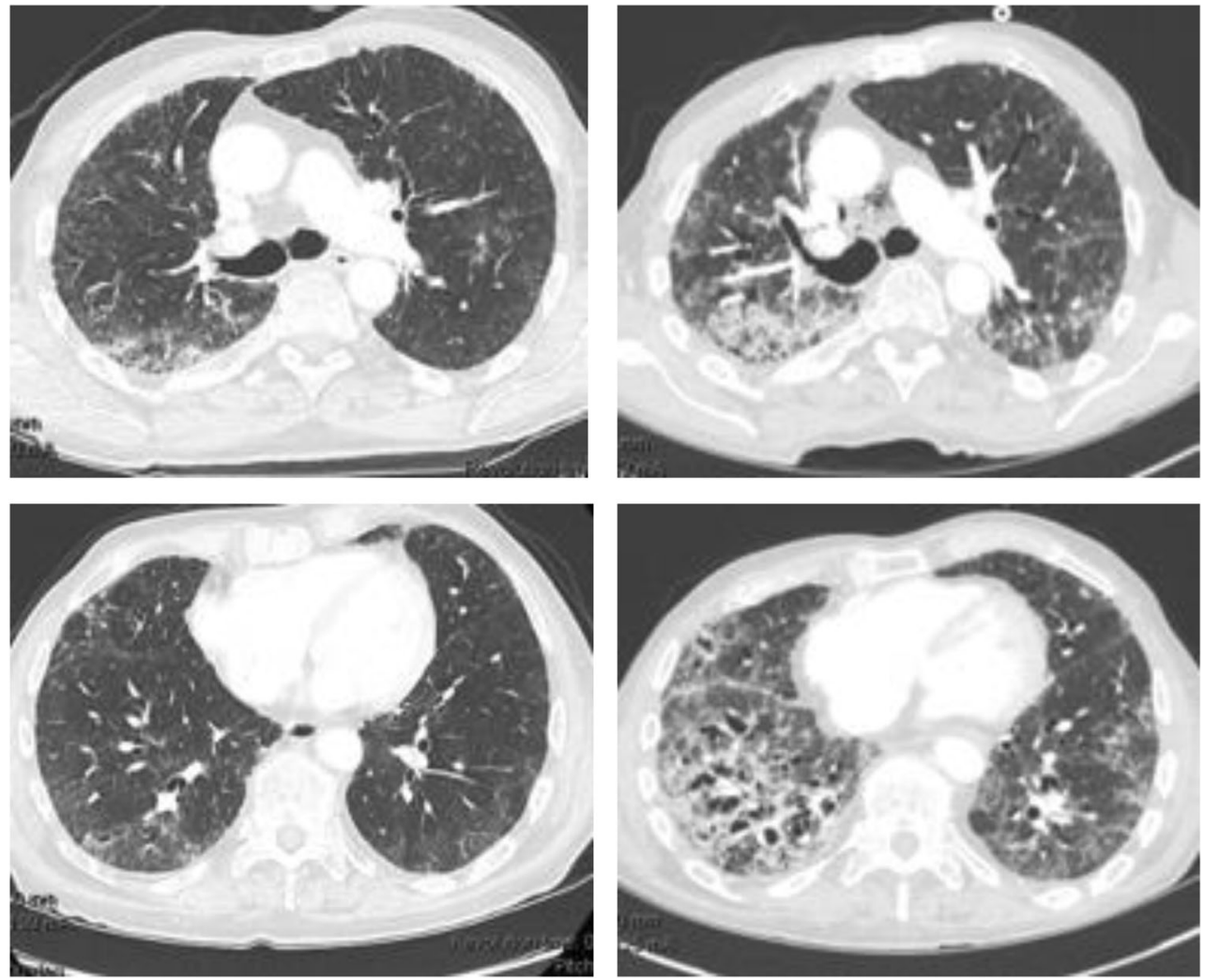

distinct lung injury patterns predominate: nonspecific interstitial pneumonitis (NSIP), organizing pneumonia (OP), and diffuse alveolar damage (DAD). Other reported findings include diffuse alveolar hemorrhage (DAH), hypersensitivity pneumonitis (HP), acute interstitial pneumonitis (AIP), acute respiratory distress syndrome (ARDS), pulmonary fibrosis (PF), and sarcoid-like reactions with lymphadenopathy [47].

$\mathrm{CT}$ imaging is the preferred imaging modality due to its higher sensitivity and specificity in the detection of interstitial lung disease [48, 49]. Ground glass opacities, consolidations, and reticular markings with sub-pleural and bibasilar predominance are common radiographic features of many lung injury patterns. Various imaging characteristics may suggest different lung injury patterns. For example, ground glass and consolidative opacities that localize predominantly to the lung periphery with the reverse halo sign are classic findings of OP (Fig. 3). Ground glass opacities, reticular infiltrates, and traction bronchiectasis with sub-pleural sparing characterizes NSIP. The typical radiographic findings of DAD/ARDS include alveolar inflammation and edema with deposition of collagen as the disease progresses. However, the classic features of each major pattern of lung injury are not pathognomonic for ICI-related pneumonitis [17]. Moreover, imaging findings are not sufficiently sensitive to distinguish ICI-related pneumonitis from other causes of pneumonitis.

Clinical presentations are highly variable and may range from asymptomatic changes on chest imaging studies, to cough, mild dyspnea, and tachypnea, or to severe dyspnea, which rapidly progresses to fulminant respiratory failure. Low-grade fevers and chest pain are less commonly described. These signs and symptoms are often mistaken for disease progression, infection, or lymphangitic carcinomatosis. Clinicians should, therefore, maintain a high index of suspicion among ICI-treated patients who present with pulmonary symptoms or abnormalities on lung imaging studies.

The time of onset of pneumonitis is broad (2.5-21 months). On average, signs and symptoms occur 4.6 months after exposure to ICI monotherapy, but may develop considerably earlier (average 2.5 months) following ICI combination therapy. Triggers for delayed pneumonitis, occurring greater than 6 months after initiation of therapy, are unknown. Nonetheless, prolonged treatment does not appear to result in an increased cumulative incidence of pneumonitis or other IrAEs. NSCLC and drug re-challenge after resolution of a prior pneumonitis event have also been associated with earlier symptom onset (median 2.7 months) [17, 25, 35, 50].

The diagnosis of ICI-related pneumonitis is established based on a compatible history and findings on CT, coupled with the exclusion of competing diagnoses, such as infection, lymphangitic spread of tumor, alveolar hemorrhage, or vasculitis (Table 1). Fiberoptic bronchoscopy with bronchoscopic alveolar lavage (BAL) is an important tool in the diagnostic work-up and should be performed early in the course of evaluation on all patients with unexplained symptomatic (grade 2 

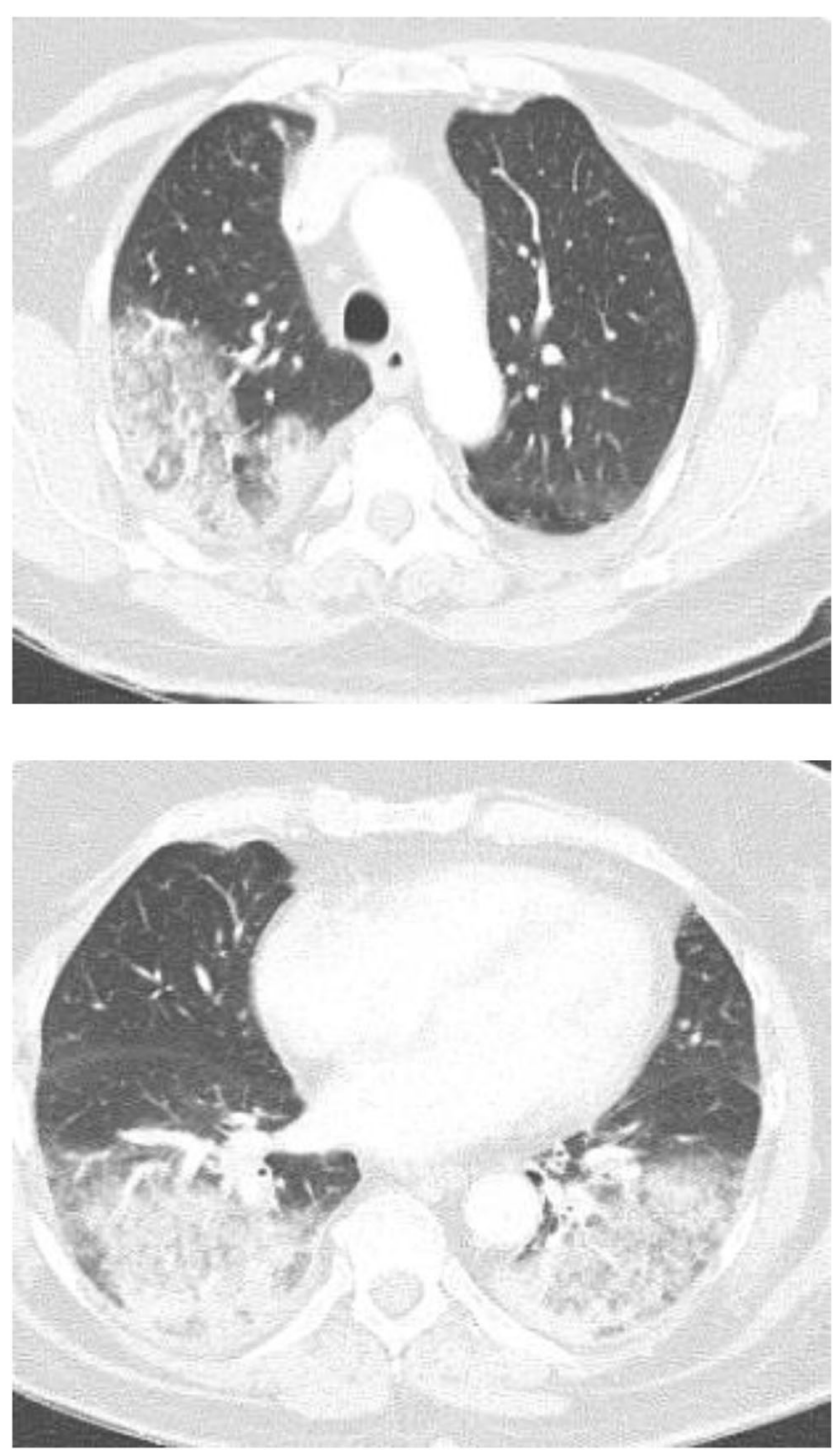

Fig. 3 Organizing pneumonia following dual ipilimumab/nivolumab therapy. Progressive dyspnea and dry cough developed 3 weeks following cycle 3 of azacitadine plus nivolumab and ipilimumab for myelodysplastic syndrome. A chest CT demonstrated multifocal consolidative and ground glass opacities involving the right upper lobe (a) and bilateral lower lobes (b). Bronchoalveolar lavage fluid was culture negative. Prominent intraluminal plugs of inflammatory debris within the small airways were seen on lung biopsy, consistent with organizing pneumonia caused by combined Nivolumab/Ipilimumab therapy

or higher) pulmonary infiltrates to rule out alternative diagnoses. Systemic corticosteroids are the cornerstone of therapy in patients with pneumonitis grades 2 or higher and, thus, bronchoscopy to exclude an infectious etiology before initiation of steroid therapy is recommended. Patients with suspected pneumonitis grades 2 or higher are Culture and PCR analysis of BAL fluid should be performed to evaluate for infectious causes of pneumonia; however, negative cultures may not definitively exclude infection. Cellular analysis of bronchoscopically obtained lavage fluid may offer important clues to the diagnoses. For example, lymphocytosis, elevated eosinophils, and predominance of CD8-positive lymphocytosis are frequent findings on BAL fluid. However, similar findings may be observed with viral pneumonias, such as those caused by CMV, thus limiting the utility of cellular analysis in differentiating pneumonitis from infection. Transbronchial and surgically obtained lung biopsies may offer additional information, particularly in the setting of unexplained lymphadenopathy or suspicious lesions suggestive of underlying tumor progression. Impairment of diffusing capacity may be one of the earliest signals of lung injury and may precede clinical and radiographic findings. Thus, pulmonary function tests (PFTs) with measurement of spirometry, lung volumes, and diffusion capacity for carbon monoxide should be performed during the initial evaluation. Serial PFTs along with 6-min walk tests (6MWT) over the course of treatment may help to guide therapy.

\section{Treatment}

Treatment approaches to ICI-related pneumonitis have not been standardized or validated in any prospective trials and are largely based on observational reports, clinical experience, and consensus opinion. These strategies are largely guided by pneumonitis grades based on CTCACE criteria. Withholding ICI therapy is recommended for all patients with suspected ICI-related pneumonitis, while the diagnostic work-up and treatment is underway. Patients with grade 1 pneumonitis may be monitored as outpatients. Chest CT imaging is recommended prior to the subsequent scheduled dose of ICI (within 3-4 weeks). If infiltrates have resolved, ICI therapy may be cautiously resumed with close follow-up. The addition of steroid therapy is recommended for pneumonitis grades 2 or higher. Patients with grade 2 pneumonitis can typically be treated as outpatients with oral prednisone, dosed at $1 \mathrm{mg} / \mathrm{kg}$ of ideal body weight/day. Drug re-challenge following resolution of infiltrates in carefully selected patients with grade 2 pneumonitis is also reasonable, with follow-up. In-patient management and permanent withdrawal of ICI therapy is recommended for all patients with grade 3-4 pneumonitis and patients with earlier-stage pneumonitis who demonstrate progression of toxicity despite drug cessation. Systemic steroids for this group of patients are typically initiated at $2 \mathrm{mg} / \mathrm{kg}$ of ideal body weight/day. As a general guide, we recommend continuing the initial dose of steroids over the ensuing 1-2 weeks, or until symptoms have returned to grade 1 (asymptomatic CT abnormalities), at which time, steroids may be slowly tapered. Pneumonitis flares may be more recalcitrant to therapy and have been reported following rapid steroid tapers. We, therefore, recommend a steroid tapering schedule over a minimum 4-6 weeks that is tailored to the severity of the pneumonitis event and response to initial therapy. 
Table 1 Differential diagnosis of IP pneumonitis

\begin{tabular}{ll}
\hline Category & Disease \\
\hline Infectious pneumonia & Bacteria, viruses (including SARs-CoV2), tuberculosis, atypical \\
& mycobacterial infection, fungi, Pneumocystis jeroveci \\
Noninfectious causes & Tumor progression, pseudoprogression; lymphangitic spread of disease \\
& Diffuse alveolar hemorrhage \\
& Aspiration pneumonitis \\
& Sarcoidosis \\
& Pulmonary vasculitis \\
& Eosinophilic pneumonia \\
& Pulmonary edema \\
Alveolar proteinosis
\end{tabular}

Prophylaxis against Pneumocystis Jeroveci pneumonia (PJP) in HIV-negative patients requiring prolonged, highdose steroid therapy remains a clinical challenge, as the dose of steroids that delimits "high dose" and the duration of steroids that defines "prolonged" have not been clearly established [51-56]. Adding to this conundrum is the fact that the predilection for PJP may vary among this patient population, rendering some patients, such as those with hematologic malignancies and those who have undergone stem cell and solid organ transplantation, more susceptible to PJP at relatively lower doses of steroids [54]. We, therefore, recommend PJP prophylaxis in our cancer patient population throughout the duration of systemic corticosteriod therapy. The addition of TNF- $\alpha$ blocking agents may increase the susceptibility to serious infections, including tuberculosis [57, 58]. Accordingly, baseline testing for tuberculosis should be performed on all patients before initiating TNF- $\alpha$ inhibiting agents. The need for gastrointestinal prophylaxis may also be appropriate in some patients undergoing prolonged steroid therapy.

Clinical improvement is generally observed within the first 48-72 h of treatment, beyond which pneumonitis is considered steroid refractory. In patients with high grade and/or steroid refractory disease, additional immunosuppressive therapy with azathioprine, mycophenolate mofetil, cyclophosphamide, and/or tocilizumab may be considered. However, the clinical impact of augmented immunosuppressive therapies and optimal dose, duration, and timing of these agents have not been studied $[9,59]$. Evidence favoring the use of intravenous immunoglobulin (IVIG) in the management of steroid refractory high-grade pneumonitis has also emerged in recent literature [60]. These studies require validation in larger prospective trials.

The use of immunosuppressive therapies in the management of ICI-related toxicities has prompted concerns regarding the potential for systemic corticosteroids to interfere with the therapeutic efficacy of immune checkpoint blockade. None of these concerns has been substantiated in any clinical data. In two separate studies, overall cancer treatment outcomes among patients receiving prolonged immunosuppression for anti-CTLA-4 induced IrAEs were not statistically different compared to patients not requiring immunosuppressive therapies [61, 62].

Twenty-five to thirty-three percent of patients may experience recurrent pneumonitis with drug re-challenge after initial resolution of signs and symptoms. Resumption of the same ICI agent after resolution of the initial IrAE unprovoked pneumonitis, occurring despite drug discontinuation has also been reported. Rapid steroid tapers (less than 5 weeks) may increase the risk of recurrent events, which tend to be earlier in onset than the first event and more severe [17, 63-65]. Life-threatening toxicities, particularly those involving the lungs, heart, or central nervous system, are considered absolute contraindications to drug re-challenge.

Fatal ICI-related pneumonitis is, fortunately, rare $(0.3 \%)$ and varies significantly between treatment regimens. In a recent large multicenter retrospective review of ICI-associated fatalities, neurologic and cardiac events associated with CTLA-4 toxic effects accounted for nearly half of all deaths. By contrast, the majority of patients who succumbed to pneumonitis had been treated with PD-1/PD-L1 blockers or PD-1/ CTLA-4 combinations [66].

\section{IrAE: sarcoid-like reactions}

Sarcoid-like reactions are uncommon IrAEs, which have been observed among 5-7\% of patients following both CTLA-4 and PD-1 blockers. De novo sarcoid-like reactions as well as exacerbation of pre-existing disease have been reported in association with both classes of ICI therapies [15, 47, 67, 68]. Enlarged mediastinal lymph nodes may occur in isolation or in association with bilateral upper- or middle-lobe predominant consolidations or ground glass opacities (Fig. 4). Concomitant sarcoid-like reactions involving the skin and kidneys have also been reported. Biopsies of enlarged lymph 

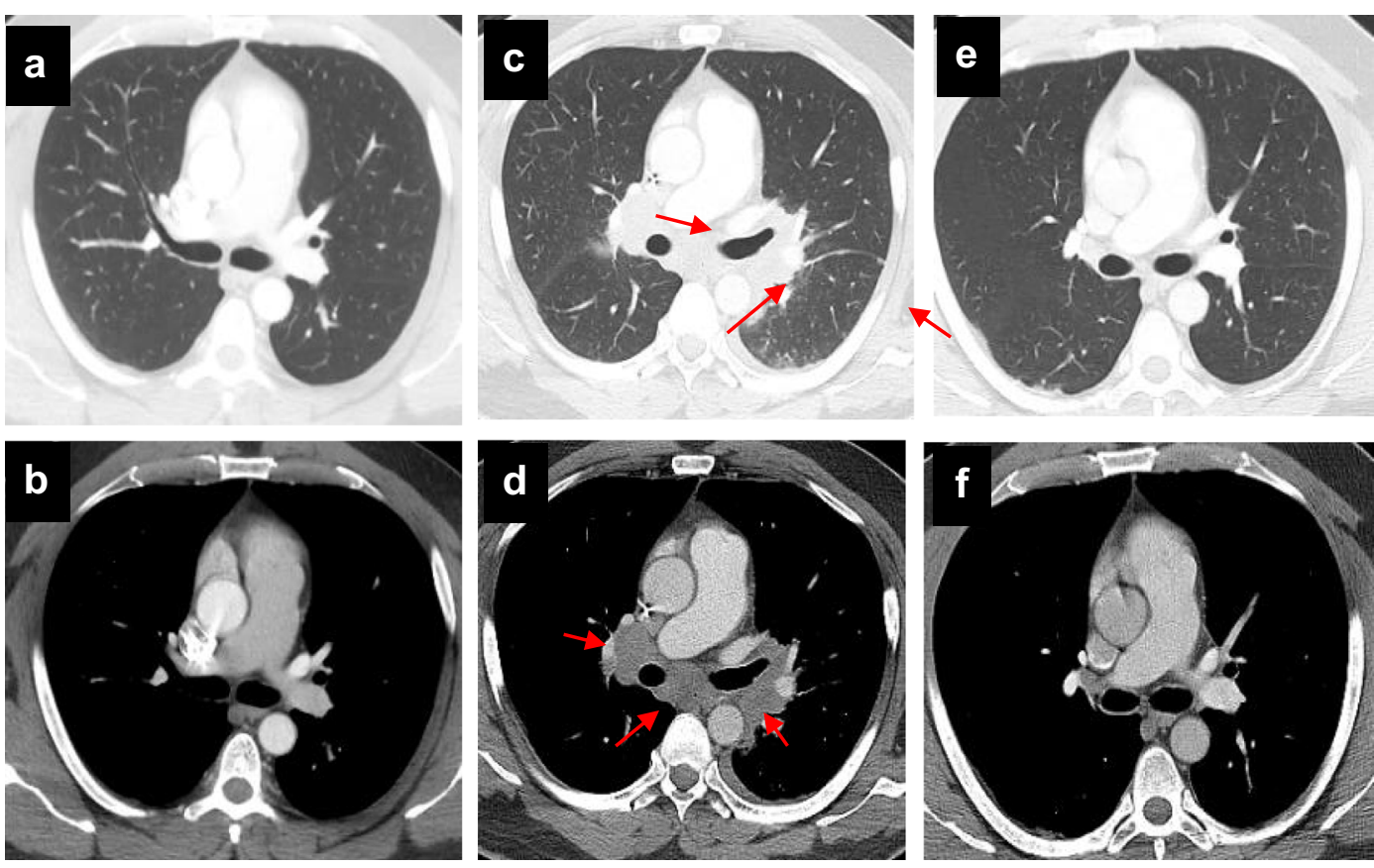

Fig. 4 ICI induced sarcoid-like reaction. Dry cough and progressive dyspnea on exertion developed in this 45-year-old man, 4 months after initiating combination Nivolumab and Ipilimumab for urothelial carcinoma. Chest CT demonstrated markedly enlarged bilateral hilar and mediastinal lymph nodes (c, d, arrows) when compared to baseline (a, b). Biopsies of the lymph nodes revealed noncaseating granulomas with no evidence of malignancy. Cultures and AFB smears of bronchoalveolar lavage fluid were negative. ICI therapy was withheld and systemic steroids were initiated for presumed ICI-induced sarcoidosis. Complete resolution of symptoms was reported after completion of 8 weeks of steroid therapy. A repeat chest CT 10 weeks after completion of steroids demonstrated regression of the mediastinal and hilar lymphadenopathy $(\mathbf{e}, \mathbf{f})$

effusions in this setting is an important tool in helping to guide decisions regarding the need for steroid therapy.

\section{$\mathrm{ICl}$ therapy in the setting of SARs-CoV-2}

The conundrum of ICI therapy in the setting of SARs-CoV-2 (COVID-19) infection is problematic on many levels, with no current evidence-based guidelines. Potential interactions between this viral illness and ICI-induced immune augmentation has created bidirectional concerns regarding the influence of these agents in exacerbating the clinical course of the viral illness and the potential impact of SARs-CoV-2 in exacerbating ICI-related adverse events. A particular emphasis has been placed on in IrAE-pneumonitis, which may closely mimic SARs-CoV-2-related pneumonia. Assumptions that coinfection with SARs-CoV-2 during ICI therapy may lead to severe complications have generated concerns regarding adaptations in treatment, albeit without any reliable scientific evidence. In fact, in the TERAVOLT study which investigated the impact of severe SARs-CoV-2 infection on patients with thoracic cancers, the type of systemic therapy including immunotherapy did not confer an increase in mortality. However, the study was not sufficiently powered in subgroup analysis to render definitive statements regarding the safety of ICI therapy in this setting [76]. 
Concerns surrounding ICI therapies in patients with concurrent SARs-CoV-2 infection persist. The need to screen patients for SARs-CoV-2 prior to initiation of ICI therapy is highly debated, as infection status is typically unknown at the time that treatment decisions relating to the initiation of ICI and other cancer therapies are being made. Questions regarding what to do with ICI therapies that are ongoing at the time of SARs-CoV-2 diagnosis are even more challenging [77, 78].

General guidelines based on expert opinion in the management of patients with grade I pneumonitis and concurrent SARs-CoV-2 include withholding therapy, adjustments to less frequent ICI dosing schedules, and cautiously continuing ICI therapy with very close monitoring [79]. Patients who develop respiratory symptoms or new pulmonary infiltrates suggestive of SARs-CoV-2 during ICI therapy should be immediately tested for the virus. Significant controversies arise for IR-pneumonitis grades 2 and higher, due in part to the attendant use of steroids in these patients. Corticosteroids represent cornerstone treatment in advanced-grade ICI-related pneumonitis, but may exacerbate respiratory sequelae of SARs-CoV-2, particularly those patients with mild disease that do not require oxygen supplementation [76, 78]. Thus, confirmation of SARs-CoV-2 with PCR testing is recommended before proceeding with corticosteroid therapy for IR-pneumonitis [78]. Bronchoscopic evaluation as part of the work-up for IR-pneumonitis in symptomatic patients with confirmed SARs-CoV-2 may facilitate viral transmission through aerosolization of respiratory droplets. We, therefore, avoid bronchoscopy in this setting, except in selected or exceptional cases.

Despite concerns regarding the potential negative impact of steroids on viral illness, corticosteroids remain the therapy of choice for patients with high-grade IR-pneumonitis. Additional immunosuppressive therapeutic options, such as anti-IL-6 which has shown therapeutic efficacy in some patients with SARs-CoV-2, may be an effective treatment strategy in steroid-refractory pneumonitis. These preliminary recommendations are made within the context of the urgent need for evidence-based guidance and should be refined as prospective data emerge.

\section{Conclusion}

ICI therapies have rapidly changed the landscape of cancer therapeutics and are currently used as standard of care for a broad range of refractory cancers. This class of drugs may trigger a spectrum of IrAEs which are generally well tolerated. Pneumonitis is less common than toxicities involving some other organ systems; however, lung injury represents a potentially lethal form of IrAEs and one of the most frequent causes of drug discontinuation. Currently, the burden of lung-related events associated with this class of drugs is low. The prevalence of pneumonitis will undoubtedly continue to grow in

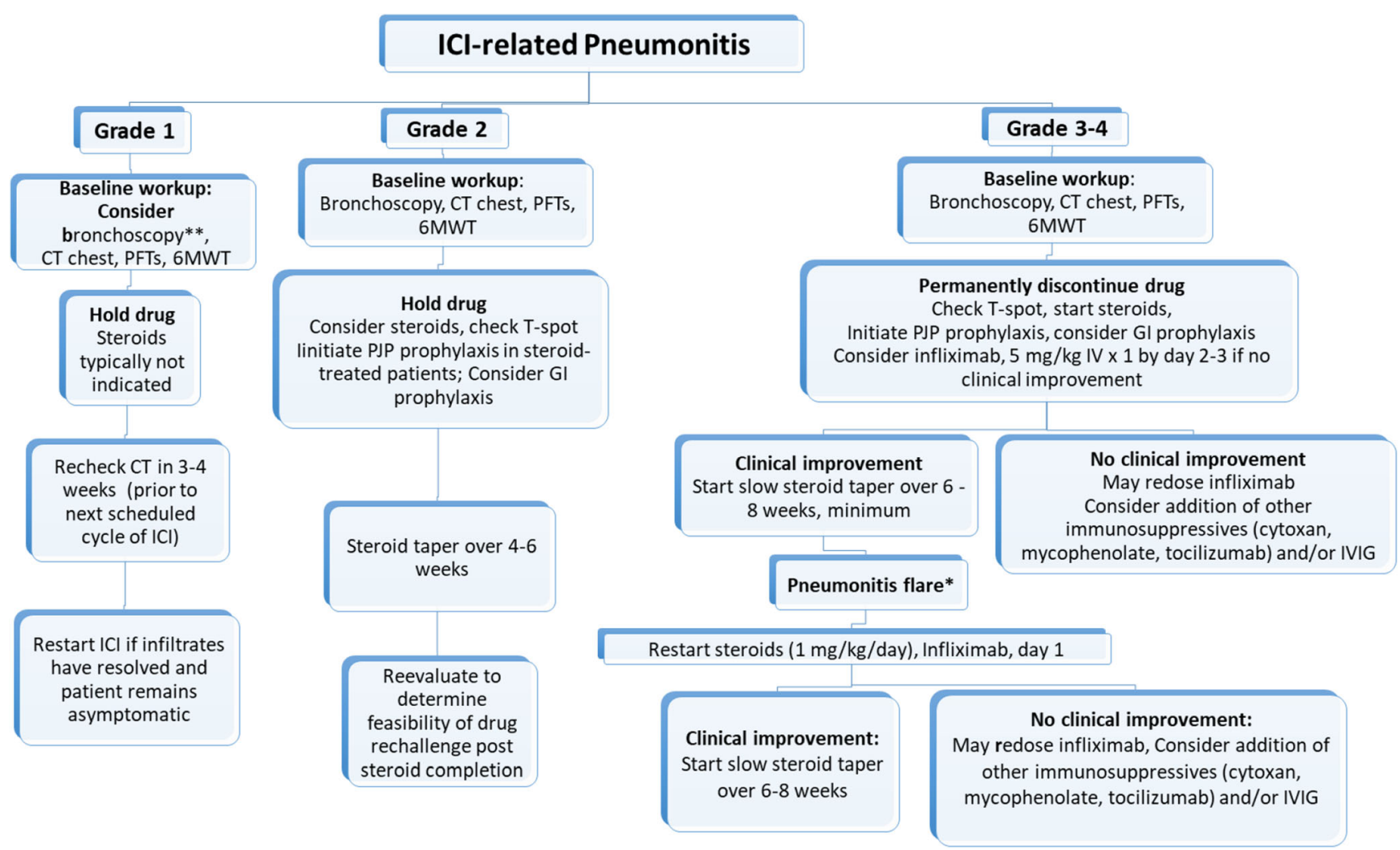

Fig. 5 Approach to management of ICI-related interstitial lung disease 
parallel with better recognition of this clinical entity coupled with the expanding indication of ICI therapies to other tumor types and the addition of these agents to complex treatment strategies that carry an additional toxicity risk. Healthcare workers providers must be aware of this emerging entity, as well as current management guidelines (Fig. 5). Early recognition and vigorous diagnostic evaluations are key. Knowledge of the diverse clinical, pathologic, and radiographic presentations of IR-pneumonitis may inform patient management and lead to improved patient outcomes. Additional studies are needed to better elucidate risk factors and comorbidities that predispose to a higher risk of lung toxicity and to establish biomarkers that are predictive of lung injury.

Authors' contributions All of the authors contributed equally to the conceptualization of the manuscript; VS drafted the manuscript, while BLR and DBJ provided clinical input and DBJ, BLR, and RA editorial oversight. All of the authors provided critical appraisal of the manuscript and approval of its submission.

Funding information Professor BL Rapoport is supported by the Cancer Association of South Africa (CANSA) and the National Research Foundation (NRF) of South Africa. Dr. I. Glezerman is supported by the NIH/NCI (Cancer Center Support Grant P30 CA008748).

\section{Compliance with ethical standards}

Conflict of interest AB, RA, JC, TC, PG, DG, RAG, and VRS have no conflict of interest to declare. MD reports grants from Novartis, other (SAB) from Neoleukin Therapeutics, personal fees from Partner Therapeutics, personal fees from Tillotts Pharma, and grants from Genentech, outside the submitted work. MG reports consultant work with Bristol Myers Squibb (BMS), and AstraZeneca, outside the submitted work. IG reports other (Stock Ownership) from Pfizer Inc. and personal fees from CytomX Inc, outside the submitted work. DBJ reports other (advisory board) from Array Biopharma, grants and other (advisory board) from BMS, other (advisory board) from Jansen, grants from Incyte, other (advisory board) from Merck, and other (advisory board) from Novartis, outside the submitted work. In addition, DBJ has a patent Co-inventor on use of CTLA-4 agonist for IAEs pending. BLR reports personal fees and other (advisory board) from Merck and Co, grants, personal fees, and other (advisory board) from BMS, grants, personal fees, and other (advisory board) from Roche South Africa, and personal fees and other (advisory board) from AstraZeneca, during the conduct of the study. MSA reports personal fees from Gilead, grants from Pfizer, and personal fees from Abbvie, outside the submitted work.

\section{References}

1. Andruska N, Mahapatra L, Hebbard C, Patel P, Paul V (2018) Severe pneumonitis refractory to steroids following anti-PD-1 immunotherapy. BMJ Case Rep 2018:225937. https://doi.org/10. 1136/bcr-2018-225937

2. Balaji A, Verde F, Suresh K, Naidoo J (2017) Pneumonitis from anti-PD-1/ PD-L1 therapy. Oncology (Williston Park) 31(10):739_ 746754

3. Koyama N, Iwase O, Nakashima E, Kishida K, Kondo T, Watanabe Y, Takahashi H, Umebayashi Y, Ogawa Y, Miura H (2018) High incidence and early onset of nivolumab-induced pneumonitis: four case reports and literature review. BMC Pulm Med 18:23. https:// doi.org/10.1186/s12890-018-0592-x

4. Louvel G, Bahleda R, Ammari S, Le Pechoux C, Levy A, Massard C, Le Pavec J, Champiat S, Deutsch E (2018) Immunotherapy and pulmonary toxicities: can concomitant immune-checkpoint inhibitors with radiotherapy increase the risk of radiation pneumonitis? Eur Respir J 51(1):1701737. https://doi.org/10.1183/13993003. 01737-2017

5. Ma K, Lu Y, Jiang S, Tang J, Li X, Zhang Y (2018) The relative risk and incidence of immune checkpoint inhibitors related pneumonitis in patients with advanced cancer: a meta-analysis. Front Pharmacol 9:1430. https://doi.org/10.3389/fphar.2018.01430

6. Nishino M, Giobbie-Hurder A, Hatabu H, Ramaiya NH, Hodi FS (2016) Incidence of programmed cell death 1 inhibitor-related pneumonitis in patients with advanced cancer: a systematic review and meta-analysis. JAMA Oncol 2(12):1607-1616. https://doi.org/ 10.1001/jamaoncol.2016.2453

7. Nishino M, Hatabu H (2017) Programmed death-1/programmed death ligand-1 inhibitor-related pneumonitis and radiographic patterns. J Clin Oncol 35(14):1628-1629. https://doi.org/10.1200/ JCO.2016.71.0434

8. Nishino M, Ramaiya NH, Awad MM, Sholl LM, Maattala JA, Taibi M, Hatabu H, Ott PA, Armand PF, Hodi FS (2016) PD-1 inhibitor-related pneumonitis in advanced cancer patients: radiographic patterns and clinical course. Clin Cancer Res 22(24): 6051-6060. https://doi.org/10.1158/1078-0432.CCR-16-1320

9. Shannon VR (2017) Pneumotoxicity associated with immune checkpoint inhibitor therapies. Curr Opin Pulm Med 23(4):305316. https://doi.org/10.1097/MCP.0000000000000382

10. Kolla BC, Patel MR (2016) Recurrent pleural effusions and cardiac tamponade as possible manifestations of pseudoprogression associated with nivolumab therapy- a report of two cases. J Immunother Cancer 4:80. https://doi.org/10.1186/s40425-016-0185-2

11. Daxini A, Cronin K, Sreih AG (2018) Vasculitis associated with immune checkpoint inhibitors-a systematic review. Clin Rheumatol 37(9):2579-2584. https://doi.org/10.1007/s10067-018-4177-0

12. van den Brom RR, Abdulahad WH, Rutgers A, Kroesen BJ, Roozendaal C, de Groot DJ, Schroder CP, Hospers GA, Brouwer E (2016) Rapid granulomatosis with polyangiitis induced by immune checkpoint inhibition. Rheumatology (Oxford) 55(6):11431145. https://doi.org/10.1093/rheumatology/kew063

13. Arellano K, Mosley JC 3rd, Moore DC (2018) Case report of ipilimumab-induced diffuse, nonnecrotizing granulomatous lymphadenitis and granulomatous vasculitis. J Pharm Pract 31(2):227229. https://doi.org/10.1177/0897190017699762

14. Gkiozos I, Kopitopoulou A, Kalkanis A, Vamvakaris IN, Judson MA, Syrigos KN (2018) Sarcoidosis-like reactions induced by checkpoint inhibitors. J Thorac Oncol 13(8):1076-1082. https:// doi.org/10.1016/j.jtho.2018.04.031

15. Kim C, Gao J, Shannon VR, Siefker-Radtke A (2016) Systemic sarcoidosis first manifesting in a tattoo in the setting of immune checkpoint inhibition. BMJ Case Rep 2016:216217. https://doi. org/10.1136/bcr-2016-216217

16. Nishino M, Sholl LM, Awad MM, Hatabu H, Armand P, Hodi FS (2018) Sarcoid-Like Granulomatosis of the lung related to immunecheckpoint inhibitors: distinct clinical and imaging features of a unique immune-related adverse event. Cancer Immunol Res 6(6): 630-635. https://doi.org/10.1158/2326-6066.CIR-17-0715

17. Naidoo J, Wang X, Woo KM, Iyriboz T, Halpenny D, Cunningham J, Chaft JE, Segal NH, Callahan MK, Lesokhin AM, Rosenberg J, Voss MH, Rudin CM, Rizvi H, Hou X, Rodriguez K, Albano M, Gordon RA, Leduc C, Rekhtman N, Harris B, Menzies AM, Guminski AD, Carlino MS, Kong BY, Wolchok JD, Postow MA, Long GV, Hellmann MD (2017) Pneumonitis in patients treated with anti-programmed death-1/programmed death ligand 1 therapy. 
J Clin Oncol 35(7):709-717. https://doi.org/10.1200/JCO.2016.68. 2005

18. Leighl NB, Hellmann MD, Hui R, Carcereny E, Felip E, Ahn MJ, Eder JP, Balmanoukian AS, Aggarwal C, Horn L, Patnaik A, Gubens M, Ramalingam SS, Lubiniecki GM, Zhang J, Piperdi B, Garon EB (2019) Pembrolizumab in patients with advanced nonsmall-cell lung cancer (KEYNOTE-001): 3-year results from an open-label, phase 1 study. Lancet Respir Med 7(4):347-357. https://doi.org/10.1016/S2213-2600(18)30500-9

19. Zhang S, Liang F, Zhu J, Chen Q (2017) Risk of pneumonitis associated with programmed cell death 1 inhibitors in cancer patients: a meta-analysis. Mol Cancer Ther 16(8):1588-1595. https:// doi.org/10.1158/1535-7163.MCT-17-0155

20. Nishijima TF, Shachar SS, Nyrop KA, Muss HB (2017) Safety and tolerability of PD-1/PD-L1 inhibitors compared with chemotherapy in patients with advanced cancer: a meta-analysis. Oncologist 22(4):470-479. https://doi.org/10.1634/theoncologist.2016-0419

21. Kwon ED, Drake CG, Scher HI, Fizazi K, Bossi A, van den Eertwegh AJ, Krainer M, Houede N, Santos R, Mahammedi H, $\mathrm{Ng} \mathrm{S}$, Maio M, Franke FA, Sundar S, Agarwal N, Bergman AM, Ciuleanu TE, Korbenfeld E, Sengelov L, Hansen S, Logothetis C, Beer TM, McHenry MB, Gagnier P, Liu D, Gerritsen WR (2014) Ipilimumab versus placebo after radiotherapy in patients with metastatic castration-resistant prostate cancer that had progressed after docetaxel chemotherapy (CA184-043): a multicentre, randomised, double-blind, phase 3 trial. Lancet Oncol 15(7):700-712. https:// doi.org/10.1016/S1470-2045(14)70189-5

22. Khunger M, Rakshit S, Pasupuleti V, Hernandez AV, Mazzone P, Stevenson J, Pennell NA, Velcheti V (2017) Incidence of pneumonitis with use of programmed death 1 and programmed death-ligand 1 inhibitors in non-small cell lung cancer: a systematic review and meta-analysis of trials. Chest 152(2):271-281. https://doi.org/10. 1016/j.chest.2017.04.177

23. Postow MA, Chesney J, Pavlick AC, Robert C, Grossmann K, McDermott D, Linette GP, Meyer N, Giguere JK, Agarwala SS, Shaheen M, Ernstoff MS, Minor D, Salama AK, Taylor M, Ott PA, Rollin LM, Horak C, Gagnier P, Wolchok JD, Hodi FS (2015) Nivolumab and ipilimumab versus ipilimumab in untreated melanoma. N Engl J Med 372(21):2006-2017. https://doi.org/10.1056/ NEJMoa1414428

24. Robert C, Long GV, Brady B, Dutriaux C, Maio M, Mortier L, Hassel JC, Rutkowski P, McNeil C, Kalinka-Warzocha E, Savage KJ, Hernberg MM, Lebbe C, Charles J, Mihalcioiu C, ChiarionSileni V, Mauch C, Cognetti F, Arance A, Schmidt H, Schadendorf D, Gogas H, Lundgren-Eriksson L, Horak C, Sharkey B, Waxman IM, Atkinson V, Ascierto PA (2015) Nivolumab in previously untreated melanoma without BRAF mutation. N Engl J Med 372(4): 320-330. https://doi.org/10.1056/NEJMoa1412082

25. Eigentler TK, Hassel JC, Berking C, Aberle J, Bachmann O, Grunwald V, Kahler KC, Loquai C, Reinmuth N, Steins M, Zimmer L, Sendl A, Gutzmer R (2016) Diagnosis, monitoring and management of immune-related adverse drug reactions of anti-PD-1 antibody therapy. Cancer Treat Rev 45:7-18. https:// doi.org/10.1016/j.ctrv.2016.02.003

26. Hassel JC, Heinzerling L, Aberle J, Bahr O, Eigentler TK, Grimm MO, Grunwald V, Leipe J, Reinmuth N, Tietze JK, Trojan J, Zimmer L, Gutzmer R (2017) Combined immune checkpoint blockade (anti-PD-1/anti-CTLA-4): evaluation and management of adverse drug reactions. Cancer Treat Rev 57:36-49. https://doi. org/10.1016/j.ctrv.2017.05.003

27. Ribas A, Shin DS, Zaretsky J, Frederiksen J, Cornish A, Avramis E, Seja E, Kivork C, Siebert J, Kaplan-Lefko P, Wang X, Chmielowski B, Glaspy JA, Tumeh PC, Chodon T, Pe'er D, Comin-Anduix B (2016) PD-1 blockade expands intratumoral memory t cells. Cancer Immunol Res 4(3):194-203. https://doi. org/10.1158/2326-6066.CIR-15-0210
28. Mitchem JB, Brennan DJ, Knolhoff BL, Belt BA, Zhu Y, Sanford DE, Belaygorod L, Carpenter D, Collins L, Piwnica-Worms D, Hewitt S, Udupi GM, Gallagher WM, Wegner C, West BL, Wang-Gillam A, Goedegebuure P, Linehan DC, DeNardo DG (2013) Targeting tumor-infiltrating macrophages decreases tumorinitiating cells, relieves immunosuppression, and improves chemotherapeutic responses. Cancer Res 73(3):1128-1141. https://doi. org/10.1158/0008-5472.CAN-12-2731

29. Gordon SR, Maute RL, Dulken BW, Hutter G, George BM, McCracken MN, Gupta R, Tsai JM, Sinha R, Corey D, Ring AM, Connolly AJ, Weissman IL (2017) PD-1 expression by tumour-associated macrophages inhibits phagocytosis and tumour immunity. Nature 545(7655):495-499. https://doi.org/10.1038/ nature22396

30. Pillai RN, Behera M, Owonikoko TK, Kamphorst AO, Pakkala S, Belani CP, Khuri FR, Ahmed R, Ramalingam SS (2018) Comparison of the toxicity profile of PD-1 versus PD-L1 inhibitors in non-small cell lung cancer: a systematic analysis of the literature. Cancer 124(2):271-277. https://doi.org/10.1002/cncr.31043

31. Ascierto PA, Del Vecchio M, Robert C, Mackiewicz A, ChiarionSileni V, Arance Fernandez AM, Schmidt H, Lebbe C, Bastholt L, Hamid O, Rutkowski P, McNeil C, Garbe C, Loquai C, Dreno B, Thomas L, Grob JJ, Hennicken D, Qureshi A, Maio M (2016) Overall survival (OS) and safety results from a phase 3 trial of ipilimumab (IP) at $3 \mathrm{mg} / \mathrm{kg}$ vs $10 \mathrm{mg} / \mathrm{kg}$ in patients with metastatic melanoma (MEL). Ann Oncol 27:vi379

32. Garon EB, Rizvi NA, Hui R, Leighl N, Balmanoukian AS, Eder JP, Patnaik A, Aggarwal C, Gubens M, Horn L, Carcereny E, Ahn MJ, Felip E, Lee JS, Hellmann MD, Hamid O, Goldman JW, Soria JC, Dolled-Filhart M, Rutledge RZ, Zhang J, Lunceford JK, Rangwala R, Lubiniecki GM, Roach C, Emancipator K, Gandhi L, KEYNOTE-001 Investigators (2015) Pembrolizumab for the treatment of non-small-cell lung cancer. N Engl J Med 372(21):2018 2028. https://doi.org/10.1056/NEJMoa1501824

33. Schoenfeld JD, Nishino M, Severgnini M, Manos M, Mak RH, Hodi FS (2019) Pneumonitis resulting from radiation and immune checkpoint blockade illustrates characteristic clinical, radiologic and circulating biomarker features. J Immunother Cancer 7(1): 112. https://doi.org/10.1186/s40425-019-0583-3

34. Voong KR, Hazell SZ, Fu W, Hu C, Lin CT, Ding K, Suresh K, Hayman J, Hales RK, Alfaifi S, Marrone KA, Levy B, Hann CL, Ettinger DS, Feliciano JL, Peterson V, Kelly RJ, Brahmer JR, Forde PM, Naidoo J (2019) Relationship between prior radiotherapy and checkpoint-inhibitor pneumonitis in patients with advanced nonsmall-cell lung cancer. Clin Lung Cancer 20(4):e470-e479. https://doi.org/10.1016/j.cllc.2019.02.018

35. Delaunay M, Cadranel J, Lusque A, Meyer N, Gounant V, MoroSibilot D, Michot JM, Raimbourg J, Girard N, Guisier F, Planchard D, Metivier AC, Tomasini P, Dansin E, Perol M, Campana M, Gautschi O, Fruh M, Fumet JD, Audigier-Valette C, Couraud S, Dalle S, Leccia MT, Jaffro M, Collot S, Prevot G, Milia J, Mazieres J (2017) Immune-checkpoint inhibitors associated with interstitial lung disease in cancer patients. Eur Respir J 50(2):1700050. https:// doi.org/10.1183/13993003.00050-2017

36. Abdel-Wahab N, Shah M, Lopez-Olivo MA, Suarez-Almazor ME (2018) Use of immune checkpoint inhibitors in the treatment of patients with cancer and preexisting autoimmune disease. Ann Intern Med 169(2):133-134. https://doi.org/10.7326/L18-0209

37. Oshima Y, Hagino N, Hara M, Ohfuji T (2018) Use of immune checkpoint inhibitors in the treatment of patients with cancer and preexisting autoimmune disease. Ann Intern Med 169(2):133. https://doi.org/10.7326/L18-0208

38. Johnson DB, Beckermann KE, Wang DY (2018) Immune checkpoint inhibitor therapy in patients with autoimmune disease. Oncology (Williston Park) 32(4):190-194 
39. Ijaz A, Khan AY, Malik SU, Faridi W, Fraz MA, Usman M, Tariq MJ, Durer S, Durer C, Russ A, Parr NNC, Baig Z, Sagar F, Ali Z, McBride A, Anwer F (2019) Significant risk of graft-versus-host disease with exposure to checkpoint inhibitors before and after allogeneic transplantation. Biol Blood Marrow Transplant 25(1):94 99. https://doi.org/10.1016/j.bbmt.2018.08.028

40. Jiménez-Ubieto A, Rodriguez A, Martinez Sánchez P, Gómez A, Rodriguez Y, Carreño-Tarragona G, Martinez-López J, Grande C (2017) Fatal graft-versus-host disease after allogeneic stem cell transplantation in a patient recently exposed to nivolumab. J Oncol Pharm Pract 25:1078155217743069-1078155217743506. https://doi.org/10.1177/1078155217743069

41. Bewersdorf JP, Stahl M, Zeidan AM (2019) Immune checkpointbased therapy in myeloid malignancies: a promise yet to be fulfilled. Expert Rev Anticancer Ther 19(5):393-404. https://doi.org/ 10.1080/14737140.2019.1589374

42. Jelinek T, Mihalyova J, Kascak M, Duras J, Hajek R (2017) PD-1/ PD-L1 inhibitors in haematological malignancies: update 2017. Immunology 152(3):357-371. https://doi.org/10.1111/imm.12788

43. Younes A, Santoro A, Shipp M, Zinzani PL, Timmerman JM, Ansell S, Armand P, Fanale M, Ratanatharathorn V, Kuruvilla J, Cohen JB, Collins G, Savage KJ, Trneny M, Kato K, Farsaci B, Parker SM, Rodig S, Roemer MG, Ligon AH, Engert A (2016) Nivolumab for classical Hodgkin's lymphoma after failure of both autologous stem-cell transplantation and brentuximab vedotin: a multicentre, multicohort, single-arm phase 2 trial. Lancet Oncol 17(9):1283-1294. https://doi.org/10.1016/S1470-2045(16)30167$\mathrm{X}$

44. El-Khoueiry AB, Sangro B, Yau T, Crocenzi TS, Kudo M, Hsu C, Kim TY, Choo SP, Trojan J, Welling THR, Meyer T, Kang YK, Yeo W, Chopra A, Anderson J, Dela Cruz C, Lang L, Neely J, Tang H, Dastani HB, Melero I (2017) Nivolumab in patients with advanced hepatocellular carcinoma (CheckMate 040): an open-label, non-comparative, phase $1 / 2$ dose escalation and expansion trial. Lancet 389(10088):2492-2502. https://doi.org/10.1016/S01406736(17)31046-2

45. Johnson DB, Sullivan RJ, Menzies AM (2017) Immune checkpoint inhibitors in challenging populations. Cancer 123(11):1904-1911. https://doi.org/10.1002/cncr.30642

46. Kehl KL, Yang S, Awad MM, Palmer N, Kohane IS, Schrag D (2019) Pre-existing autoimmune disease and the risk of immunerelated adverse events among patients receiving checkpoint inhibitors for cancer. Cancer Immunol Immunother 68(6):917-926. https://doi.org/10.1007/s00262-019-02321-z

47. Berthod G, Lazor R, Letovanec I, Romano E, Noirez L, Mazza Stalder J, Speiser DE, Peters S, Michielin O (2012) Pulmonary sarcoid-like granulomatosis induced by ipilimumab. J Clin Oncol 30(17):e156-e159. https://doi.org/10.1200/JCO.2011.39.3298

48. Kaneko M, Eguchi K, Ohmatsu H, Kakinuma R, Naruke T, Suemasu K, Moriyama N (1996) Peripheral lung cancer: screening and detection with low-dose spiral CT versus radiography. Radiology 201(3):798-802. https://doi.org/10.1148/radiology. 201.3.8939234

49. Grenier P, Valeyre D, Cluzel P, Brauner MW, Lenoir S, Chastang C (1991) Chronic diffuse interstitial lung disease: diagnostic value of chest radiography and high-resolution CT. Radiology 179(1):123132. https://doi.org/10.1148/radiology.179.1.2006262

50. Nishino M, Chambers ES, Chong CR, Ramaiya NH, Gray SW, Marcoux JP, Hatabu H, Janne PA, Hodi FS, Awad MM (2016) Anti-PD-1 inhibitor-related pneumonitis in non-small cell lung cancer. Cancer Immunol Res 4(4):289-293. https://doi.org/10.1158/ 2326-6066.CIR-15-0267

51. Stern A, Green H, Paul M, Vidal L, Leibovici L (2014) Prophylaxis for pneumocystis pneumonia (PCP) in non-HIV immunocompromised patients. Cochrane Database Syst Rev 10:CD005590. https:// doi.org/10.1002/14651858.CD005590.pub3
52. Green H, Paul M, Vidal L, Leibovici L (2007) Prophylaxis of pneumocystis pneumonia in immunocompromised non-HIVinfected patients: systematic review and meta-analysis of randomized controlled trials. Mayo Clin Proc 82(9):1052-1059. https://doi. org/10.4065/82.9.1052

53. Park JW, Curtis JR, Moon J, Song YW, Kim S, Lee EB (2018) Prophylactic effect of trimethoprim-sulfamethoxazole for pneumocystis pneumonia in patients with rheumatic diseases exposed to prolonged high-dose glucocorticoids. Ann Rheum Dis 77(5):644-649. https://doi.org/10.1136/annrheumdis-2017-211796

54. Yale SH, Limper AH (1996) Pneumocystis carinii pneumonia in patients without acquired immunodeficiency syndrome: associated illness and prior corticosteroid therapy. Mayo Clin Proc 71(1):5-13. https://doi.org/10.4065/71.1.5

55. Sepkowitz KA (1996) Pneumocystis carinii pneumonia without acquired immunodeficiency syndrome: who should receive prophylaxis? Mayo Clin Proc 71(1):102-103. https://doi.org/10. 4065/71.1.102

56. Sepkowitz KA, Brown AE, Armstrong D (1995) Pneumocystis carinii pneumonia without acquired immunodeficiency syndrome. More patients, same risk. Arch Intern Med 155(11):1125-1128. https://doi.org/10.1001/archinte.1995.00430110015002

57. Murdaca G, Spano F, Contatore M, Guastalla A, Penza E, Magnani O, Puppo F (2015) Infection risk associated with anti-TNF-alpha agents: a review. Expert Opin Drug Saf 14(4):571-582. https://doi. org/10.1517/14740338.2015.1009036

58. Fernandez-Ruiz M, Aguado JM (2018) Risk of infection associated with anti-TNF-alpha therapy. Expert Rev Anti-Infect Ther 16(12): 939-956. https://doi.org/10.1080/14787210.2018.1544490

59. Puzanov I, Diab A, Abdallah K, Bingham CO 3rd, Brogdon C, Dadu R, Hamad L, Kim S, Lacouture ME, LeBoeuf NR, Lenihan D, Onofrei C, Shannon V, Sharma R, Silk AW, Skondra D, SuarezAlmazor ME, Wang Y, Wiley K, Kaufman HL, Ernstoff MS (2017) Managing toxicities associated with immune checkpoint inhibitors: consensus recommendations from the Society for Immunotherapy of Cancer (SITC) Toxicity Management Working Group. J Immunother Cancer 5(1):95. https://doi.org/10.1186/s40425-0170300-z

60. Petri CR, Patell R, Batalini F, Rangachari D, Hallowell RW (2019) Severe pulmonary toxicity from immune checkpoint inhibitor treated successfully with intravenous immunoglobulin: case report and review of the literature. Respir Med Case Rep 27:100834. https:// doi.org/10.1016/j.rmcr.2019.100834

61. Downey SG, Klapper JA, Smith FO, Yang JC, Sherry RM, Royal RE, Kammula US, Hughes MS, Allen TE, Levy CL, Yellin M, Nichol G, White DE, Steinberg SM, Rosenberg SA (2007) Prognostic factors related to clinical response in patients with metastatic melanoma treated by CTL-associated antigen- 4 blockade. Clin Cancer Res 13(22 Pt 1):6681-6688. https://doi.org/10.1158/ 1078-0432.CCR-07-0187

62. Arriola E, Wheater M, Krishnan R, Smart J, Foria V, Ottensmeier C (2015) Immunosuppression for ipilimumab-related toxicity can cause pneumocystis pneumonia but spare antitumor immune control. Oncoimmunology 4(10):e1040218. https://doi.org/10.1080/ 2162402X.2015.1040218

63. Santini FC, Rizvi H, Plodkowski AJ, Ni A, Lacouture ME, Gambarin-Gelwan M, Wilkins O, Panora E, Halpenny DF, Long NM, Kris MG, Rudin CM, Chaft JE, Hellmann MD (2018) Safety and efficacy of re-treating with immunotherapy after immunerelated adverse events in patients with NSCLC. Cancer Immunol Res 6:1093-1099. https://doi.org/10.1158/2326-6066.CIR-170755

64. Asher N, Marom EM, Ben-Betzalel G, Baruch EN, SteinbergSilman Y, Schachter J, Shapira-Frommer R, Markel G (2019) Recurrent pneumonitis in patients with melanoma treated with 
immune checkpoint inhibitors. Oncologist 24(5):640-647. https:// doi.org/10.1634/theoncologist.2018-0352

65. Pollack MH, Betof A, Dearden H, Rapazzo K, Valentine I, Brohl AS, Ancell KK, Long GV, Menzies AM, Eroglu Z, Johnson DB, Shoushtari AN (2018) Safety of resuming anti-PD-1 in patients with immune-related adverse events (IrAEs) during combined anti-CTLA-4 and anti-PD1 in metastatic melanoma. Ann Oncol 29(1):250-255. https://doi.org/10.1093/annonc/mdx642

66. Wang DY, Salem JE, Cohen JV, Chandra S, Menzer C, Ye F, Zhao S, Das S, Beckermann KE, Ha L, Rathmell WK, Ancell KK, Balko JM, Bowman C, Davis EJ, Chism DD, Horn L, Long GV, Carlino MS, Lebrun-Vignes B, Eroglu Z, Hassel JC, Menzies AM, Sosman JA, Sullivan RJ, Moslehi JJ, Johnson DB (2018) Fatal toxic effects associated with immune checkpoint inhibitors: a systematic review and meta-analysis. JAMA Oncol 4(12):1721-1728. https://doi.org/ 10.1001/jamaoncol.2018.3923

67. Reuss JE, Kunk PR, Stowman AM, Gru AA, Slingluff CL Jr, Gaughan EM (2016) Sarcoidosis in the setting of combination ipilimumab and nivolumab immunotherapy: a case report \& review of the literature. J Immunother Cancer 4:94. https://doi.org/10. 1186/s40425-016-0199-9

68. Tirumani SH, Ramaiya NH, Keraliya A, Bailey ND, Ott PA, Hodi FS, Nishino M (2015) Radiographic profiling of immune-related adverse events in advanced melanoma patients treated with ipilimumab. Cancer Immunol Res 3(10):1185-1192. https://doi. org/10.1158/2326-6066.CIR-15-0102

69. Ramstein J, Broos CE, Simpson LJ, Ansel KM, Sun SA, Ho ME, Woodruff PG, Bhakta NR, Christian L, Nguyen CP, Antalek BJ, Benn BS, Hendriks RW, van den Blink B, Kool M, Koth LL (2016) IFN-gamma-producing T-helper 17.1 cells are increased in sarcoidosis and are more prevalent than T-helper type 1 cells. Am J Respir Crit Care Med 193(11):1281-1291. https://doi.org/10.1164/rccm. 201507-1499OC

70. von Euw E, Chodon T, Attar N, Jalil J, Koya RC, Comin-Anduix B, Ribas A (2009) CTLA4 blockade increases Th17 cells in patients with metastatic melanoma. J Transl Med 7:35. https://doi.org/10. 1186/1479-5876-7-35

71. Tanaka K, Yanagihara T, Ikematsu Y, Inoue H, Ota K, Kashiwagi E, Suzuki K, Hamada N, Takeuchi A, Tatsugami K, Eto M, Ijichi K, Oda Y, Otsubo K, Yoneshima Y, Iwama E, Nakanishi Y, Okamoto I (2018) Detection of identical T cell clones in peritumoral pleural effusion and pneumonitis lesions in a cancer patient during immune-checkpoint blockade. Oncotarget 9(55): 30587-30593. https://doi.org/10.18632/oncotarget.25743

72. Atallah-Yunes SA, Kadado AJ, Soe MH (2019) Pericardial effusion due to pembrolizumab-induced immunotoxicity: a case report and literature review. Curr Probl Cancer 43(5):504-510. https://doi.org/ 10.1016/j.currproblcancer.2019.01.001

73. Kushnir I, Wolf I (2017) Nivolumab-induced pericardial tamponade: a case report and discussion. Cardiology 136:49-51. https://doi.org/10.1159/000447053

74. Vittorio A, Sharma R, Siejka D, Bhattarai K, Hardikar A (2018) Recurrent pericardial effusion while receiving nivolumab for metastatic lung adenocarcinoma: case report and review of the literature. Clin Lung Cancer 19:e717-e720. https://doi.org/10.1016/j. cllc.2018.05.010

75. Yamasaki M, Daido W, Saito N, Funaishi K, Okada T, Kawamoto K, Matsumoto Y, Matsumoto N, Taniwaki M, Ohashi N, Hattori N (2019) Pericardial effusion with tamponade in lung cancer patients during treatment with nivolumab: a report of two cases. Front Oncol 9:4. https://doi.org/10.3389/fonc.2019.00004

76. Garassino MC, Whisenant JG, Huang LC, Trama A, Torri V, Agustoni F, Baena J, Banna G, Berardi R, Bettini AC, Bria E, Brighenti M, Cadranel J, De Toma A, Chini C, Cortellini A, Felip E, Finocchiaro G, Garrido P, Genova C, Giusti R, Gregorc V, Grossi F, Grosso F, Intagliata S, La Verde N, Liu SV, Mazieres J, Mercadante E, Michielin O, Minuti G, Moro-Sibilot D, Pasello G, Passaro A, Scotti V, Solli P, Stroppa E, Tiseo M, Viscardi G, Voltolini L, Wu YL, Zai S, Pancaldi V, Dingemans AM, Van Meerbeeck J, Barlesi F, Wakelee H, Peters S, Horn L (2020) COVID-19 in patients with thoracic malignancies (TERAVOLT): first results of an international, registry-based, cohort study. Lancet Oncol 21:914-922

77. Russano M, Citarella F, Napolitano A, Dell'Aquila E, Cortellini A, Pantano F, Vincenzi B, Tonini G, Santini D (2020) COVID-19 pneumonia and immune-related pneumonitis: critical issues on differential diagnosis, potential interactions, and management. Expert Opin Biol Ther:1-5

78. Naidoo J, Reuss JE, Suresh K, Feller-Kopman D, Forde PM, Mehta Steinke S, Rock C, Johnson DB, Nishino M, Brahmer JR (2020) Immune-related (IR)-pneumonitis during the COVID-19 pandemic: multidisciplinary recommendations for diagnosis and management. J Immunother Cancer 8:e00984

79. Horby P, Lim WS, Emberson JR, Mafham M, Bell JL, Linsell L, Staplin N, Brightling C, Ustianowski A, Elmahi E, Prudon B, Green C, Felton T, Chadwick D, Rege K, Fegan C, Chappell LC, Faust SN, Jaki T, Jeffery K, Montgomery A, Rowan K, Juszczak E, Baillie JK, Haynes R, Landray MJ (2020) Dexamethasone in hospitalized patients with covid-19 - preliminary report. N Engl J Med

Publisher's note Springer Nature remains neutral with regard to jurisdictional claims in published maps and institutional affiliations.

\section{Affiliations}

\section{Vickie R. Shannon ${ }^{1} \cdot$ Ronald Anderson ${ }^{2} \cdot$ Ada Blidner $^{3} \cdot$ Jennifer Choi $^{4} \cdot$ Tim Cooksley $^{5,6} \cdot$ Michael Dougan $^{7,8}$. Ilya Glezerman ${ }^{9}$ • Pamela Ginex ${ }^{10}$ • Monica Girotra ${ }^{11,12}$ • Dipti Gupta ${ }^{12}$ • Douglas B. Johnson ${ }^{13}$. Maria E. Suarez-Almazor ${ }^{14} \cdot$ Bernardo L. Rapoport $^{2,15}$ (D)}

1 Department of Pulmonary Medicine, The University of Texas MD Anderson Cancer Center, Houston, TX, USA

2 Department of Immunology, Faculty of Health Sciences, University or Pretoria, Corner Doctor Savage Road and Bophelo Road, Pretoria 0002, South Africa

3 Laboratory of Immunopathology, Institute of Biology and Experimental Medicine-CONICET, Buenos Aires, Argentina
4 Division of Oncodermatology, Robert H. Lurie Comprehensive Cancer Center, Northwestern University Feinberg School of Medicine, Chicago, IL, USA

5 Manchester University Foundation Trust, Manchester, UK

6 The Christie, University of Manchester, Manchester, UK

7 Massachusetts General Hospital, Boston, MA, USA 
8 Harvard Medical School, Boston, MA, USA

9 Renal Service, Department of Medicine, Memorial Sloan-Kettering Cancer Center, New York, NY, USA

10 Oncology Nursing Society, Pittsburgh, PA, USA

11 Endocrine Division, Department of Medicine, Weill Cornell Medical College (MG, AF), New York, NY, USA

12 Department of Medicine (DJB), Memorial Sloan-Kettering Cancer Center (MC), New York, NY, USA
13

Department of Medicine, Vanderbilt University Medical Center and Vanderbilt Ingram Cancer Center, Nashville, TN, USA

14 Section of Rheumatology and Clinical Immunology, University of Texas MD Anderson Cancer Center, Houston, USA

15 The Medical Oncology Centre of Rosebank, 129 Oxford Road, Saxonwold, Johannesburg 2196, South Africa 